\title{
The Spore Surface in Pithomyces chartarum
}

\author{
BY W. S. BERTAUD \\ Dominion Physical Laboratory, D.S.I.R., Lower Hutt, \\ New Zealand \\ ISOBEL M. MORICE \\ Fats Research Laboratory, D.S.I.R., Wellington, New Zealand \\ D. W. RUSSELL AND A. TAYLOR \\ Ruakura Animal Research Station, Hamilton, New Zealand
}

(Received 15 February 1963)

\section{SUMMARY}

Crystalline spicules of sporidesmolides, together with some lipid, form the surface layer of spores of Pithomyces chartarum. The formation of the spicules is controlled by the amino acids present in the culture medium.

\section{INTRODUCTION}

Observations by Miss J. M. Dingley indicated that young spores of Pithomyces chartarum were echinulate, the echinulation becoming less marked at maturity; electron microscopy showed that a spicular layer covered the surface of the spores. These observations prompted the conjecture of Russell \& Brown (1959) that the sporidesmolides might occur as a surface coating. Circumstantial evidence in support of this idea was provided when it was shown that there was a relationship between the number of spores produced in cultures of $\boldsymbol{P}$. chartarum and the weight of sporidesmolides which could be isolated therefrom (Done, Mortimer, Taylor \& Russell, 1961; Dingley, Done, Taylor \& Russell, 1962). Evidence from electron microscopy, $\mathrm{X}$-ray diffraction, chemical analysis and fermentation experiments which establish the nature of the surface layer are presented here.

\section{METHODS}

Organisms. Electron micrographs of spores of the following isolates were kindly provided by Miss J. M. Dingley (Plant Disease Division, D.S.I.R., Auckland, New Zealand) from her collection. Definitions of the terms 'isolate', 'laboratory isolate' and the significance of the numerals are given by Dingley et al. (1962). Isolates s68a, s66a and s66 were obtained from pastures at Dargaville, New Zealand, in 1959. Isolate $\mathrm{C}$ was described by Dingley et al. (1962). Isolate FE 4(o) was from pastures at Gippsland, Victoria, Australia obtained in May 1959 and FE4(s) is a laboratory isolate analogous to isolate c derived from FE 4(o). Isolate DAOM/57103 was obtained in $\mathbf{1 9 5 7}$ during an aerial survey over Manhattan, Riley County, Kansas, U.S.A. and is held in the collection of the Central Experimental Farm, Canada Department of Agriculture, Ottawa. Isolate $\mathrm{c}$ was used for all culture work. 
Electron microscopy. Whole spores were examined by mounting them on carboncoated collodion films and surface replicas were prepared as follows. Spores were dispersed on microscope slides coated with polyvinyl alcohol. Water vapour was then condensed on the slides to soften the polyvinyl alcohol which was allowed to harden and the spores brushed off, leaving negative impressions on the surface. Collodion $(2 \%, \mathrm{w} / \mathrm{v}$, in amyl acetate) was then applied and after drying the composite film was stripped from the slide and floated, collodion uppermost, on hot water to remove polyvinyl alcohol. The collodion film bearing positive impressions of the spores was shadowed with uranium, coated with carbon and mounted on specimen grids. The collodion was removed with amyl acetate and the carbon replica examined in a Philips EM 100 electron microscope.

$X$-ray diffraction. The crystalline component was examined by $\mathrm{X}$-ray analysis with $\mathrm{CuK}_{\alpha}$ radiation collimated to a beam of $0.25 \mathrm{~mm}$. diameter, and a flat film with a specimen to film distance of about $3 \mathrm{~mm}$., accurately calibrated against the X-ray diagram of silver. Powder diagrams were obtained from samples of the total sporidesmolide fraction from whole normal spores, and from pseudo-replicas of spores containing material stripped from the surface. To make the pseudo-replicas a polyvinyl alcohol impression was prepared as for electron microscopy. On brushing off the spores, the spicules were left embedded in the polyvinyl alcohol which was then coated with carbon. When the polyvinyl alcohol was removed with hot water, the spicules were left attached to the carbon film, which was rolled up and inserted in the specimen holder of the diffraction camera.

Cultivation of organisms. Spores for benzene extraction were obtained from isolate c, grown on rye (Secale cereale) grain media (Lloyd \& Clarke, 1959); these were supplied by Dr R. H. Thornton (Soil Bureau, Taita, near Wellington, New Zealand). For the fermentation experiments isolate $\mathrm{C}$ was grown in surface culture on potato carrot medium (solids content $20 \mathrm{mg} . / \mathrm{ml}$., Done et al. 1961) without addition of glucose or ammonium salts. The medium was dispensed into several equal volumes; one volume was used as a control and one of the amino acids (California Corporation for Biochemical Research, Los Angeles, U.S.A.; chromatographically pure) to be investigated was added to each of the other portions. The media thus obtained were dispensed in $100 \mathrm{ml}$. amounts into pint milk bottles which were then plugged with cottonwool and autoclaved at $120^{\circ}$ for $15 \mathrm{~min}$. When cold the bottles containing the various media were randomly distributed, inoculated as described previously (Done et al. 1961), laid horizontally in a stack and incubated at $25^{\circ}$ for 7 days.

Benzene extraction of spores. The fungal tissue (mostly spores, $15.5 \mathrm{~g}$. dry weight) was stirred with benzene $(50 \mathrm{ml}$.) in a sintered glass funnel (no. 4, average pore diameter 5-15 $\mu$ ) and the extract sucked through; the whole process took about $1 \mathrm{~min}$. A small portion (10-20 mg.) of the residue was removed for electron microscopy. This procedure was carried out 10 times. The residue after the tenth wash was heated under reflux for $15 \mathrm{~min}$. with diethyl ether $(25 \mathrm{ml})+$. methanol $(25 \mathrm{ml}$. $)$ and filtered hot. This process was performed 5 times and the 5 extracts combined as fraction 11. The residue was heated under reflux with ether $(25 \mathrm{ml})+$. methanol $(25 \mathrm{ml})+$. hydrochloric acid $(10 \mathrm{~N} ; 0.5 \mathrm{ml}$.) as described for fraction 11 and the 5 extracts were combined as fraction 12. Each of the fractions (1-12) was evaporated to dryness, the residues weighed and extracted with light petroleum (b.p. 
$40-60^{\circ} ; 6$ times with $5 \mathrm{ml}$.) at $20^{\circ}$. The extracts were evaporated to dryness. The light petroleum-insoluble portions were extracted with chloroform and, in the case of fractions 11 and 12, the chloroform-soluble material recrystallized from acetone. The material soluble in light petroleum from fractions 1-10 was combined, saponified and the fatty acids converted to methyl esters; methyl esters of the fatty acids from fractions 11 and 12 were prepared similarly. The esters were examined by gas-liquid chromatography with a chromatograph constructed in the Fats Research Laboratory as described by Morice (1962).

Isolation of amino acids from spent medium. The filtered media from 7-day cultures were lyophilized. The resulting solids $(1 \mathrm{~g}$.) in water $(20 \mathrm{ml}$.) was centrifuged (15 min., $1800 \mathrm{rev} . / \mathrm{min}$.) and the supernatant fluid run on a column of Amberlite IR $120\left(\mathrm{H}^{+}\right.$form, $24 \mathrm{~g}$., $22 \times 1.9 \mathrm{~cm}$., $\equiv 80 \mathrm{ml}$. N-acid) ion exchange resin. The column was washed with dilute acetic acid $(0.5 \mathrm{~N} ; 75 \mathrm{ml}$.) and then with water $(150 \mathrm{ml}$.). The amino acid was eluted with triethylamine $(2 \mathrm{~N}$; in $20 \%, \mathrm{v} / \mathrm{v}$ acetone in water; $280 \mathrm{ml}$.). The first $40 \mathrm{ml}$. of eluate were discarded, the remainder collected and evaporated to dryness. The residue was taken up in the minimum volume of warm water, the solution treated with charcoal $(0.5 \mathrm{~g}$. Darco G 60 , Atlas Powder Co., Wilmington, Delaware, U.S.A.), filtered and the filtrate treated with ethanol until turbid. The colourless crystals which separated after standing for $24 \mathrm{hr}$. at $2^{\circ}$ were collected and identified from their infra-red spectra. All optical rotations quoted were measured on amino acids purified in this way.

Mycelium dry weights, nitrogen determinations, spore counts and sporidesmolide estimations were carried out as described by Done et al. (1961). Hydrolysis of depsipeptides and the chromatography of amino acids were carried out as described by Russell, Synge, Taylor \& White (1962). The proportion of the various amino acids present in hydrolysates was determined as described by Russell (1960). Infrared spectra were obtained on specimens dispersed in potassium bromide disks by using a Perkin Elmer 'Infracord' model 137 spectrophotometer.

\section{RESULTS}

When replicas of the spore surface of Pithomyces chartarum were examined in the electron microscope, the cuticle was found to be completely covered by a dense coat of fine rod-like structures (Pl. 1, fig. 1). Profile electron micrographs (Pl. 1 fig. 2) showed that these structures were delicate spicules up to $800 \mathrm{~m} \mu$ long and $30-50 \mathrm{~m} \mu$ thick, attached by one end to the spore and tending to stand out from the spore surface at right angles. Identical surface structures were observed on all the isolates examined. The appearance of the spore surface in electron micrographs resembled the appearance of the waxy coating seen in electron micrographs of higher plants (Juniper \& Bradley, 1958). An attempt was made to remove the spicules by washing the spore with organic solvents; light petroleum had no effect; benzene or diethyl ether removed the spicules completely. The result of such an experiment is shown in Pl. 2, fig. 3; there are no spicules and there is a smooth cuticle, interrupted by the projections seen in the light microscope. It was concluded that the spicules were not an integral part of the spore wall.

To obtain information about the chemical nature of the spicular coating a sample of fungal material consisting mostly of spores was subjected to a series of brief washes with benzene. Electron micrographs of spores removed after each wash made 
possible correlation between the disappearance of spicules and the appearance of material in the extract. The weights of the extracts and some of their physical properties are given in Table 1. Fractions 1-10 were completely soluble when treated with light petroleum and then chloroform, but $79 \%$ of fraction 11 and $89 \%$ of fraction 12 were insoluble in these solvents. Only $40 \%$ of that part of fraction 11 soluble in chloroform was sporidesmolides; the nature of the remainder (m.p. $120-135^{\circ}$ ) was not determined. The infrared spectra of the chloroform-soluble parts

Table 1. Physical properties of the solutes of benzene washes and of ether-methanol extracts of spores of Pithomyces chartarum

\begin{tabular}{|c|c|c|c|c|}
\hline \multirow[b]{2}{*}{$\begin{array}{c}\text { Fraction } \\
\text { no. }\end{array}$} & \multirow{2}{*}{$\begin{array}{l}\text { Weight of } \\
\text { fraction } \\
\text { soluble in } \\
\text { light } \\
\text { petroleum } \\
\text { (mg.) }\end{array}$} & \multicolumn{3}{|c|}{ Sporidesmolide fraction } \\
\hline & & $\begin{array}{c}\text { Weight } \\
\text { (mg.) }\end{array}$ & $\begin{array}{c}\text { m.p. } \\
\left(^{\circ}\right)\end{array}$ & $\begin{array}{c}{[\alpha]_{D}^{19}} \\
\left({ }^{\circ}\right)\end{array}$ \\
\hline 1 benzene & 50 & 82 & $230-236$ & -203 \\
\hline 2 & 15 & 91 & $240-245$ & -207 \\
\hline 3 & 5 & 78 & $238-246$ & -205 \\
\hline 4 & 2 & 58 & $259-263$ & -205 \\
\hline 5 & 2 & 59 & 243-262 & -198 \\
\hline 6 & 1 & 42 & $241-260$ & -210 \\
\hline 7 & 1 & 32 & 243-260 & -200 \\
\hline 8 & 1 & 31 & $285-245$ & -205 \\
\hline 9 & 1 & 20 & 233-242 & -207 \\
\hline 10 & 1 & 13 & 239-257 & -195 \\
\hline 11 ether + & 137 & 41 & $245-260$ & -185 \\
\hline 12$\}$ methanol & 66 & 0 & - & - \\
\hline
\end{tabular}

Table 2. Fatty acid composition (mole \%) of lipids found in extracts of spores of Pithomyces chartarum

$\mathrm{C}_{12}$, etc. = straight chain saturated fatty acid having 12 carbon atoms, e.g. stearic acid $=\mathrm{C}_{18} ;{ }^{*} \mathrm{C}_{18}^{3}=$ etc. $=$ straight chain unsaturated fatty acid having 18 carbon atoms and 3 double bonds; $*(b r)=$ alkyl branched chain; tr. = trace.

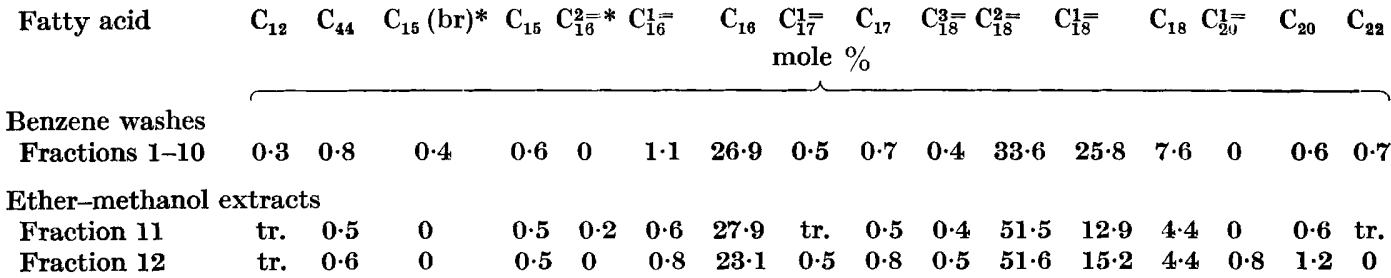

of fractions 1-10 were identical and were indistinguishable from the infrared spectrum of the total sporidesmolide fraction (Russell et al. 1962). All of the chloroform-soluble parts of fractions 1-10 provided valine, leucine, $N$-methylleucine and isoleucine after acid hydrolysis and the proportions of these amino acids were the same as those obtained after hydrolysis of the total sporidesmolide fraction. The light petroleum-soluble fraction was principally lipid. The fatty acids present in the lipid from the combined fractions 1-10 and from fractions 11 and 12, and their relative proportions are given in Table 2 . The fatty acid composition of fractions 1-10 differed from that of fractions 11 and 12 in that they (fractions 1-10) 
contained less linoleic acid and more oleic and stearic acids. The analysis of fractions 11 and 12 was like that reported by Hartman, Morice \& Shorland (1962) for the total lipid of spores of Pithomyces chartarum. Fractions 1-10 contained $26 \%$ of unsaponifiable lipid and fractions 11 and 12, 12\%. In Fig. 1 the amount of sporidesmolide remaining on the spore is plotted as a function of the number of washes with benzene.

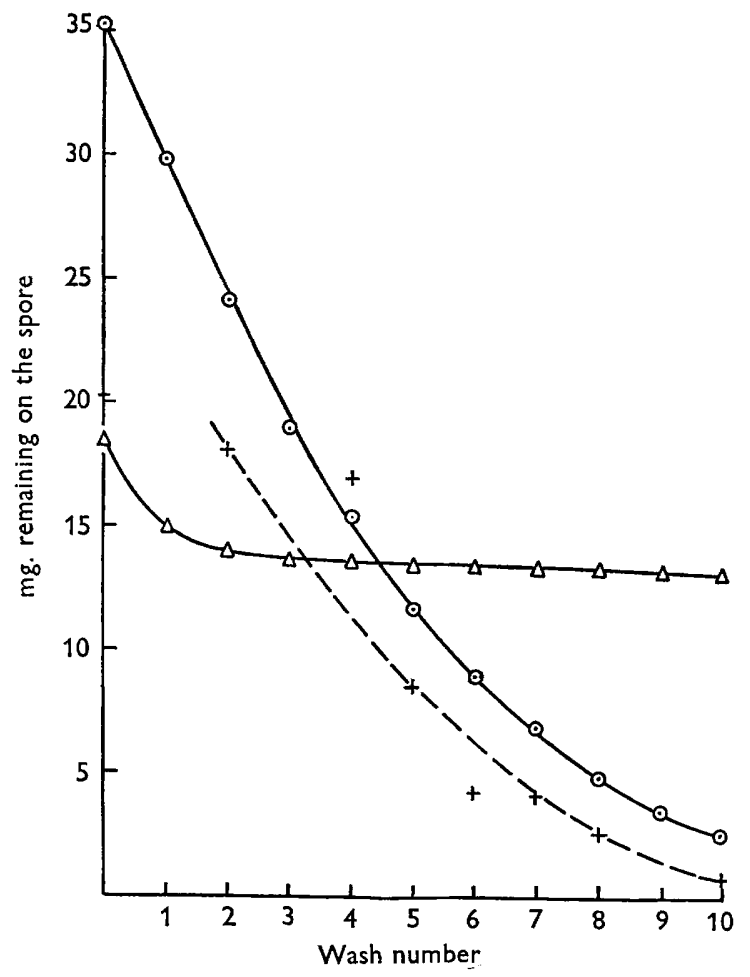

Fig. 1. Extraction curves showing the behaviour of surface constituents during benzene extraction. $\odot-\multimap$, Sporidesmolides by analysis ; $\triangle-\triangle$, lipids by analysis ; $+\cdots++$, spicule weight by electron microscopy.

Replicas of spores after each benzene wash were examined in the electron microscope; a progressive decrease in the spicular coat was apparent. For comparison with the analytical results estimates were made of the weight of spicular material in each fraction; for this the density of each fraction was assumed to be the same as that of the total sporidesmolide fraction, which was found by centrifugation in a sucrose density gradient to lie between 1.1 and $1.2 \mathrm{~g} . / \mathrm{ml}$. In making measurements of spicules it was found that length could be ascertained much more readily than thickness. A relationship was found between length and thickness by measuring a large number of clearly defined spicules. Subsequently each spicule was measured for length alone and the relationship used to assign a volume and thus weight. By this means a weight of spicular material per unit area of spore surface was found. The spores were assumed to be prolate spheroids, $15 \mu \times 10 \mu$, of unit density before drying to constant weight; this enabled the amount of spicules to be expressed as a fraction of the spore weight. The results are plotted in Fig. 1. Good agreement 
with the weight of sporidesmolides was obtained; most of the points lay on a curve of the same shape as that derived from the chemical analysis. This result is strong evidence that the spicules are composed of sporidesmolide. The displacement of the two curves may indicate the presence of a sporidesmolide component not incorporated in the spicules, but it is doubtful whether the method is sufficiently accurate to make the difference significant.

Further experimental evidence for the nature of the spore coat was sought by making use of the metabolic antagonism of isoleucine and valine (see, for example, Gladstone, 1939). Sporidesmolide I contains two valyl residues but no isoleucine (Russell, 1962). The possibility existed that the organism might be grown in the presence of isoleucine without affecting growth but with inhibition of formation of sporidesmolide I. Electron micrographs of spores of such cultures could then be compared with those of normal spores.

Effect of DL-leucine, DL-valine, and DL-isoleucine on the growth of Pithomyces chartarum. Adding DL-leucine or DL-isoleucine to cultures increased their growth. The effect was like that reported by Done et al. (1961) after addition of ammonium salts and glutamine. The increase in amount of growth was largely independent of the concentration of the starting medium or, in the range examined, of the initial concentration of added amino acid. Only the added amino acid was observed in culture filtrates 7 days after inoculation and quantitative estimation revealed that it accounted for about half the nitrogen present. The isoleucine recovered from culture filtrates was optically active and the direction of the rotation indicated that the L-isomer had been preferentially used by the mould. By contrast, leucine recovered in the same way was optically inactive. Addition of DL-valine also stimulated growth, its effect being greater than that of leucine or isoleucine; it was calculated, on the basis of nitrogen analyses, that $50 \%$ of the added valine was incorporated by the mould. The valine recovered from culture filtrates 7 days after inoculation was optically active; in one experiment where the initial DL-valine concentration was $2 \mathrm{mg} . / \mathrm{ml}$. the recovered amino acid was almost pure $\mathrm{D}$-valine.

Effect of DL-leucine, DL-isoleucine, and DL-valine on sporidesmolide production. The yield of sporidesmolides from cultures grown on media supplemented with DLleucine was the same as that obtained from control cultures grown on unmodified media. The physical properties of the metabolites were identical with those of the total sporidesmolide fraction as described by Russell et al. (1962) and the proportion of the amino acid fragments (leucine, valine, $N$-methylleucine, isoleucine) was also the same $(1: 2: 1: 0 \cdot 2)$. Sporidesmolide production from cultures enriched with DL-valine was greater than that from controls, usually by a factor of 2 or 3 , and this ratio was independent of the strength of the starting medium and of the amount of added DL-valine within the range examined. The depsipeptide mixture produced had the same physical properties as the total sporidesmolide fraction from control cultures and gave the same amino acids on hydrolysis.

The addition of isoleucine caused marked changes in the properties and decreased the quantity of depsipeptides produced; in general, weaker starting media produced a greater effect. The isolated depsipeptide fraction from isoleucine cultures had m.p. 221 ${ }^{\circ}$. It did not sublime and gave an infrared spectrum different from that of the total sporidesmolide fraction obtained from control cultures. On hydrolysis leucine, valine, $N$-methylleucine and isoleucine were obtained in equal proportions. 
The quantities of depsipeptides given in Table 5 were calculated from optical rotation data (Done et al. 1961) by assuming that the composition of the depsipeptides was the same as that described by Russell et al. (1962). As shown above, this assumption is untenable. Therefore the quantity of depsipeptides produced was also determined gravimetrically and was found in all cases to be about $25 \%$ higher

Table 3. Physical properties of amino acids recovered from culture filtrates of Pithomyces chartarum after growth for $\mathbf{7}$ days at $\mathbf{2 5}^{\circ}$

\begin{tabular}{|c|c|c|c|c|c|c|}
\hline \multirow[b]{2}{*}{ Expt. no. } & \multicolumn{4}{|c|}{ Recovered amino acid } & \multirow[b]{2}{*}{$\begin{array}{l}c \text { in } \\
\text { acetic } \\
\text { acid }\end{array}$} & \multirow[b]{2}{*}{$\begin{array}{c}\% \mathrm{D} \\
\text { isomer }\end{array}$} \\
\hline & Identity & $\begin{array}{l}\text { Weight } \\
\text { recovered } \\
(\mathrm{mg} . / \mathrm{ml} .)\end{array}$ & $\begin{array}{c}\text { Weight } \\
\text { added } \\
(\mathrm{mg} . / \mathrm{ml} .)\end{array}$ & $\begin{array}{c}{[\alpha]_{D}^{20 *}} \\
\left({ }^{\circ}\right)\end{array}$ & & \\
\hline 1 & Isoleucine & $2 \cdot 3$ & 5 & $-\mathbf{3} \cdot \mathbf{3}$ & $0 \cdot 9$ & $52 \cdot 5$ \\
\hline 2 & Isoleucine & $1 \cdot 0$ & $2 \cdot 5$ & -15 & 0.5 & 62 \\
\hline 5 & Leucine & $3 \cdot 0$ & 5 & $0 \cdot 0$ & 1.7 & 50 \\
\hline 6 & Valine & $2 \cdot 0$ & $\mathbf{5}$ & -23 & 0.9 & $66 \cdot 5$ \\
\hline 7 & Valine & $0 \cdot 15$ & $2 \cdot 5$ & $-\mathbf{5 5}$ & 0.8 & 88 \\
\hline
\end{tabular}

* $[\alpha]_{\mathrm{D}}^{20}$ Specific optical rotation using sodium light at $20^{\circ}$.

$c$ in acetic acid: optical rotations were determined in acetic acid solution at the concentrations stated in the column.

$\% \mathrm{D}$ isomer: \% enantiomorph having the absolute configuration of the $\mathrm{D}$ series.

Table 4. Sporidesmolide production by Pithomyces chartarum in surface culture for 7 days at $25^{\circ}$ on media supplemented with $5 \mathrm{mg}$. DL-valine/ml.

\begin{tabular}{|c|c|c|c|}
\hline Expt. no. & $\begin{array}{l}\text { Dry weight of } \\
\text { fungus at harvest } \\
\text { (mg./ml.) }\end{array}$ & $\begin{array}{c}\text { Spores } \\
\left(\times 10^{-5} / \mathrm{ml} .\right)\end{array}$ & $\begin{array}{c}\text { Sporidesmolides } \\
\text { (mg./l.) }\end{array}$ \\
\hline $7 *$ & $5 \cdot 9$ & 130 & 148 \\
\hline 8 & $10 \cdot 3$ & 117 & 206 \\
\hline $8 \dagger$ & $6 \cdot 2$ & 275 & 279 \\
\hline 6 & $11 \cdot 4(7 \cdot 1)$ & $380(125)$ & $374(120)$ \\
\hline
\end{tabular}

* Initial concentration of added amino acid $2.5 \mathrm{mg} . / \mathrm{ml}$. ; initial medium concentration $10 \mathrm{mg}$. $/ \mathrm{ml}$. $\dagger 14$ days growth.

Values for controls given in parentheses or in Table 5.

Table 5. Sporidesmolide production by Pithomyces chartarum in surface culture for 7 days at $25^{\circ}$ on media supplemented with $5 \mathrm{mg}$. DL-isoleucine $/ \mathrm{ml}$.

$\begin{array}{cccc}\text { Expt. no. } & \begin{array}{c}\text { Dry weight of } \\ \text { fungus at harvest } \\ (\mathbf{m g} / \mathrm{ml} .)\end{array} & \begin{array}{c}\text { Spores } \\ \left(\times 10^{-5} / \mathrm{ml} .\right)\end{array} & \begin{array}{c}\text { Sporidesmolides } \\ (\mathbf{m g} . / \text {. })\end{array} \\ 7 * & 4 \cdot 8(4 \cdot 1) & 92(71) & 2 \cdot 0(76) \\ 4 & \mathbf{5 \cdot 4 ( 4 \cdot 5 )} & 116(89) & 28(45) \\ 1 & 6 \cdot 6(7 \cdot 7) & 145(134) & 31(163) \\ 8 \dagger & \mathbf{7 \cdot 2}(7 \cdot 6) & 228(195) & 39(179) \\ 8 & 9 \cdot 7(8 \cdot 8) & 137(175) & 35(147) \\ 3 & 7 \cdot 9(7 \cdot 4) & 230(228) & 41(125) \\ 3 \ddagger & \mathbf{7 \cdot 9} & 240 & 46\end{array}$

* Initial medium concentration $10 \mathrm{mg} . / \mathrm{ml}$.

$\dagger$ 14 days' growth.

Initial amino acid concentration $2.5 \mathrm{mg} . / \mathrm{ml}$.

Figures in parentheses are results obtained on control cultures, i.e. no supplementary amino acid. Expts. 7 and 4 represent the limits of the observed effect. 
than the values given in Table 5. The significance of this result cannot be assessed until more is known about the complexity of this mixture of depsipeptides.

Spores from the isoleucine, valine and control cultures described above were examined by electron microscopy. Estimations of the weight of spicules from the electron micrographs gave the value $7.9 \mathrm{mg}$. spicules/g. spores for 14-day control cultures (Expt. 8). The values obtained for comparable cultures (Expt. 8, Tables 4 and 5) enriched with valine and isoleucine were $12 \cdot 4$ and $3 \cdot 2 \mathrm{mg}$. spicules/g. spores, respectively. All these values are lower than those given in Tables 4 and 5 and it is presumed that this is due to abrasive mechanical loss during the drying and grinding procedures used after harvest. It is clear, nevertheless, that adding isoleucine to the culture medium decreased the amount of spicule material on the spore surface.

$X$-ray diffraction. The total sporidesmolide fraction gave a diffraction pattern with a very strong reflexion at $12.2 \AA$ and strong reflexions at $7 \cdot 0,6 \cdot 1,5 \cdot 2,4.9$ and $4 \cdot 6 \AA$. The powder diagram from a sample of whole spores (Pl. 2, fig. 4) gave a clear sporidesmolide pattern, together with diffuse haloes which are tentatively attributed to a chitin-like substance in the spore wall. A pseudo-replica containing spicules stripped from the spore surface also gave a clear sporidesmolide pattern but contained no chitin reflexions (Pl. 2, fig. 5).

\section{DISCUSSION}

The presence of spiny processes on the spores of certain strains of Streptomyces was reported by Flaig, Beutelspacher, Küster \& Segler-Holzweissig (1952) and several isolates from New Zealand soils have been noted to produce spores with spiny outgrowths (Vernon, 1955). Fragile easily detached spines were observed on the surface of spores of Streptomyces toyocaensis so 927 by Arai \& Kuroda (1962). Although certain strains of Streptomyces are known to produce depsipeptides (see, for example, Vining \& Taber, 1957), no information of this nature is available about the organisms mentioned above and our observations (Vernon \& Bertaud, unpublished) indicate that such spines are not removed by washing with organic solvents.

Lipid and sporidesmolides were removed from the surface of spores of Pithomyces chartarum at different rates (Fig. 1) by successive washes with benzene; most of the lipid washed from the spores appeared in the first two fractions. Since fractions 1-10 comprised only $28 \%$ of the total lipid and differed in composition from the total spore lipid it seems reasonable to conclude that the washing process removed only material which was present on the surface. By contrast, sporidesmolides were eluted more slowly and $8 \%$ remained at the end of the washing procedure. Because of the very large surface presented by the spicules, of the order of $100 \mathrm{~m}^{2} . / \mathrm{g}$., equilibrium with solvents is likely to be approached rapidly under the conditions of these experiments; but the solubility of sporidesmolides in benzene is probably too low to account for the observed extraction curve. However, unknown factors such as differences in solubility of the various sporidesmolides and abrasion of colloidal particles during the washing procedure may complicate the results. A second possibility is that the spicules are attached to the spore surface by a benzene-soluble cementing material and pass through the filter as a colloidal suspension. This hypothesis is supported by the fact that little variation was observed in the distribution of spicule lengths during the extraction, whereas if they had been going into 
solution a progressive decrease in length would be expected to occur. As the spicules were not removed by washing with light petroleum, the cementing material would presumably appear in the chloroform-soluble fraction and would thus account in part for the discrepancy between weight of sporidesmolides isolated and estimated spicule weight, though no evidence has been obtained for the presence of such an entity.

The numerical correlations between the surface spicules and the amount of sporidesmolides were obtained by two independent experimental approaches. Despite the uncertainty as to the mechanism of extraction with benzene and the reason for the low values of spicule weight on the surface of spores from surface cultures, there is little doubt that the spicules are composed of sporidesmolides and that these compounds are present mainly, if not entirely, on the spore surface. An alternative possibility that the spicules are made of a benzene-soluble precursor which is transformed into sporidesmolides during the isolation procedure is excluded by the $\mathrm{X}$-ray results.

It seems worth while to consider whether the presence of these surface compounds, which are of unusual chemical structure and represent a high (3-4\%) proportion of the spore weight, can be used to help understand the sporulation process : does the biosynthesis of the sporidesmolides present unusual features which might provide a clue to the physiology of spore formation? Butler, Russell \& Clarke (1962) showed that radioactive valine was incorporated in high yield into sporidesmolide $\mathrm{I}$, and they were unable to show the presence of intermediate products. The effects of DL-valine and DL-isoleucine on sporidesmolide formation recall studies (e.g. Gladstone, 1939) on the role of these amino acids in protein synthesis by microorganisms, and particularly their effect on the production of actinomycin IV by Streptomyces chrysomallus (Katz, Waldron \& Meloni, 1961); thus the biosynthesis of sporidesmolide I shows some similarity to protein synthesis. Spore formation is attended by heavy utilization of nitrogen of the medium (Dingley et al. 1962); presumably some of this nitrogen metabolism is connected with the synthesis of protein ultimately found in the spores. It seems reasonable to suggest that biosynthesis of sporidesmolides proceeds simultaneously and is an unusual feature of the metabolism of Pithomyces chartarum which is associated with sporulation. If this analysis be correct, consideration of the structure of sporidesmolide I suggests that a derivative of valine such as $\alpha$-ketoisovaleric acid may be an important precursor, since residues derivable from such a compound can account for more than $60 \%$ of the molecular weight of the metabolite. The precursor might arise during catabolism of mycelium protein.

The spores of Pithomyces chartarum are remarkably water-repellent, a property which may be important in their dispersal (Crawley, Campbell \& Smith, 1962); in this and in the control of water movement in and out of the spore, the surface sporidesmolides and lipids may well play a part. However, since the sporidesmolides are closely related to antibacterial substances, e.g. valinomycin (Brockmann \& Geeren, 1957), one function of the spore coat might be to inhibit the growth of predatory bacteria. Lingappa \& Lockwood (1961), discussing the well-known fungistatis of soil, suggested that metabolites with fungistatic properties are produced by micro-organisms whose growth is supported by resting fungal spores. Hence the possibility may be envisaged of an analogous stasis of $\boldsymbol{P}$. chartarum in 
pasture as being induced by stimulating the formation of sporidesmolide-deficient spores. Such a biological system would provide a means of determining experimentally the role of $\boldsymbol{P}$. chartarum in facial eczema (Done, Mortimer \& Taylor, 1960).

\section{REFERENCES}

Arai, T. \& Kuroda, S. (1962). Fine structure of spiny spores of Streptomyces. J. Bact. $83,924$.

Brockmann, H. \& Geeren, H. (1957). Valinomycin II; Antibiotika aus Actinomyceten XXVII. Die Konstitution des Valinomycins. Annalen, 603, 216.

Butler, G. W., Russell, D. W. \& Clarke, R. T. J. (1962). Incorporation of ${ }^{14} \mathrm{C}$-labelled amino acids into sporidesmolide I by Pithomyces chartarum (Sporidesmium bakeri). Biochim. biophys. Acta, 58, 507.

Crawley, W. E., Campbeli, A. G. \& Smith, J. D. (1962). Movement of spores of Pithomyces chartarum on leaves of rye grass. Nature, Lond. 193, 295.

Dingley, J. M., Done, J., Taylor, A. \& Russell, D. W. (1962). The production of sporidesmin and sporidesmolides by wild isolates of Pithomyces chartarum. J. gen. Microbiol. 29, 127.

Done, J., Mortimer, P. H., Taylor, A. \& Russell, D. W. (1961). The production of sporidesmin and sporidesmolides by Pithomyces chartarum. J. gen. Microbiol. 26, 207.

Done, J., Mortimer, P. H. \& TAYLOR, A. (1960). Some observations on field cases of facial eczema: liver pathology, and determinations of serum bilirubin, cholesterol, transaminase and alkaline phosphatase. Res. vet. Sci. 1, 76.

Flaig, W., Beutelspacher, H., Küster, E. \& Segler-Holzweissig, G. (1952). Beiträge zur Physiologie und Morphologie der Streptomyceten. Plant \& Soil, 4, 118.

GLADSTONE, G. P. (1939). Inter-relationships between amino acids in the nutrition of B. anthracis. Brit. J. exp. Path. 20, 189.

Hartman, L., Morice, I. M. \& Shorland, F. B. (1962). Further studies on the lipids from Pithomyces chartarum (Sporidesmium bakeri) and related fungi. Biochem. J. 82, 76.

Juniper, B. E. \& Bradley, D. E. (1958). The carbon replica technique in the study of the ultrastructure of leaf surfaces. J. Ultrastructure Res. 2, 16.

Katz, E., Waldron, C. R. \& Meloni, M. L. (1961). Role of valine and isoleucine as regulators of actinomycin peptide formation by Streptomyces chrysomallus. J. Bact. 82,600 .

LingaPPa, B. T. \& Lockwood, J. L. (1961). The nature of the widespread soil fungistasis. J. gen. Microbiol. 26, 473.

LlOYd, A. B. \& Clarke, R. T. J. (1959). Spore production by Sporidesmium bakeri on rye-corn (Secale cereale). N.Z. J. Agric. Res. 2, 1084.

Morice, I. M. (1962). Seed fats of the New Zealand Agavaceae. J. Sci. Fd Agric. 13, 666.

Russell, D. W. (1960). Ninhydrin as a reagent for $N$-methylamino acids. J. Chromatog. 4, 251 .

Russell, D. W. (1962). Depsipeptides of Pithomyces chartarum: the structure of sporidesmolide I. J. chem. Soc. p. 753.

Russell, D. W. \& Brown, M. E. (1959). Sporidesmolic acid B; a hydroxyacyldipeptide from Sporidesmium bakeri. Biochim. biophys. Acta, 38, 382.

Russell, D. W., Synge, R. L. M., Taylor, A. \& White, E. P. (1962). Similarity of depsipeptides from Pithomyces chartarum and from pasture samples from 'facial eczema' areas. J. chem. Soc. p. $\mathbf{5 5 4}$.

Vernon, T. R. (1955). Spore formation in the genus Streptomyces. Nature, Lond. 176, 935.

Vining, L. C. \& TABER, W. A. (1957). Amidomycin, a new antibiotic from a Streptomyces species. Canad. J. Chem. 35, 1109. 


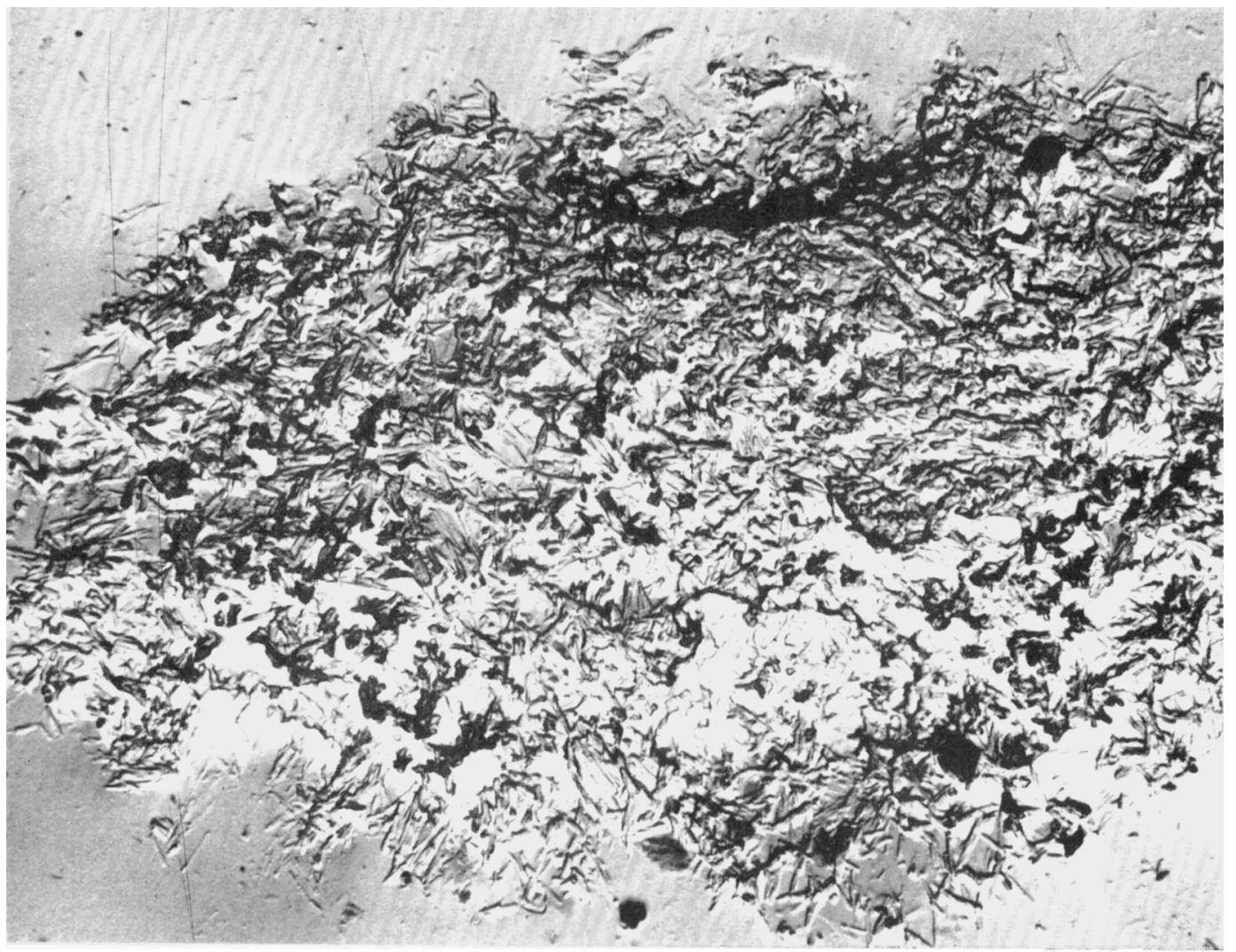

Fig. 1

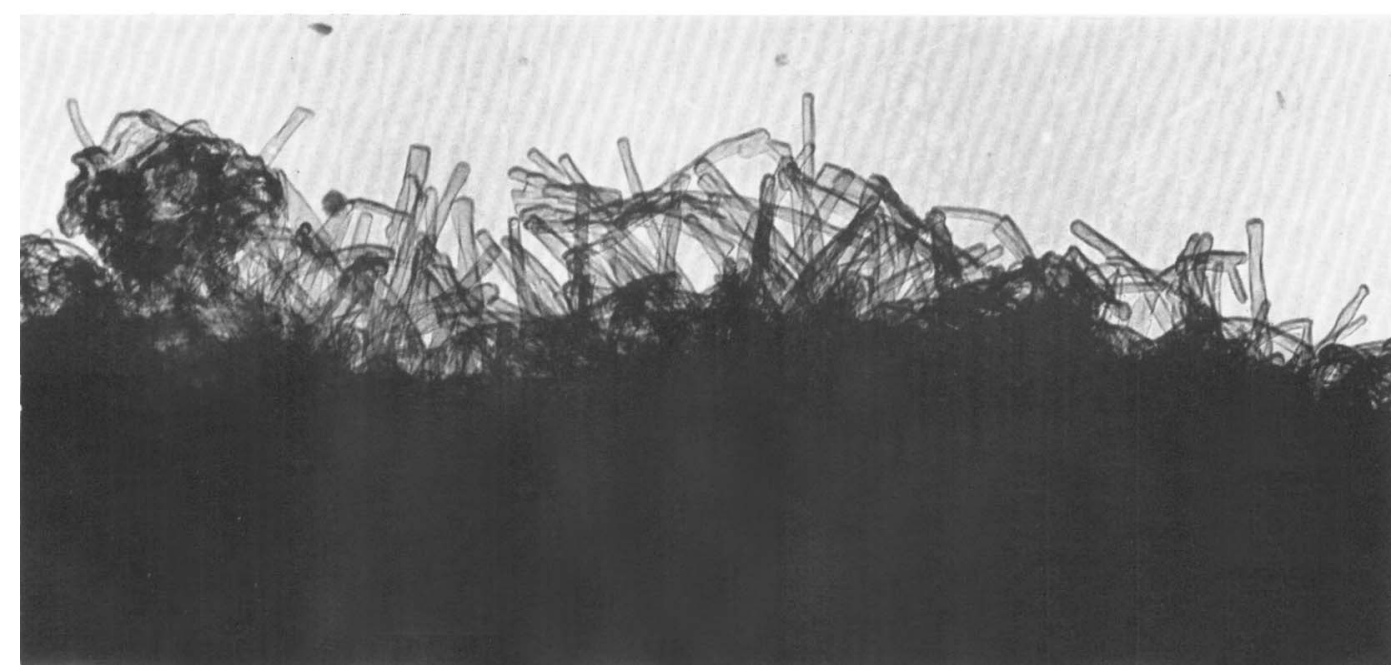

Fig. 2

W. S. BERTAUD AND OTHERS

(Facing p. 394) 


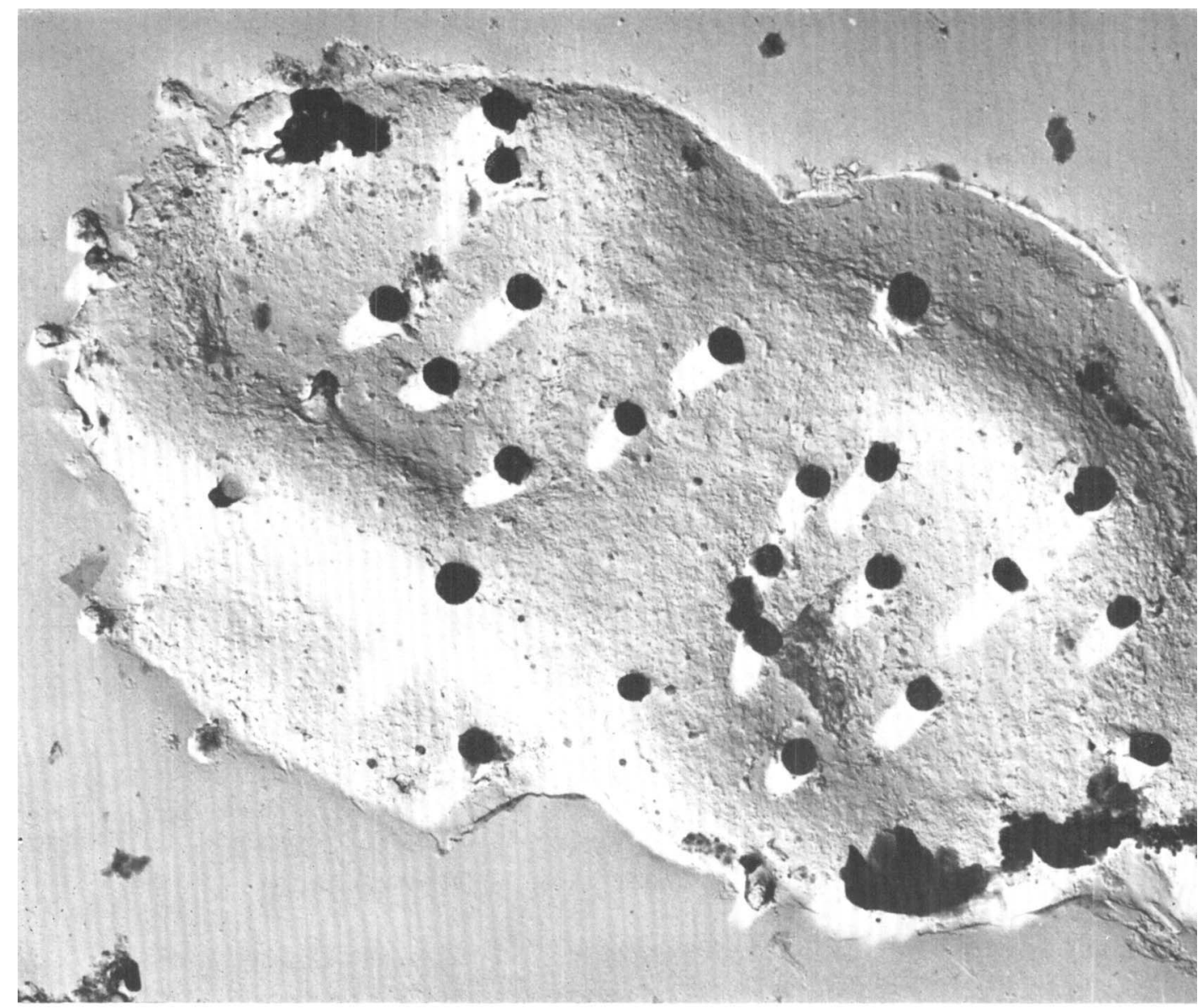

Fig. 3
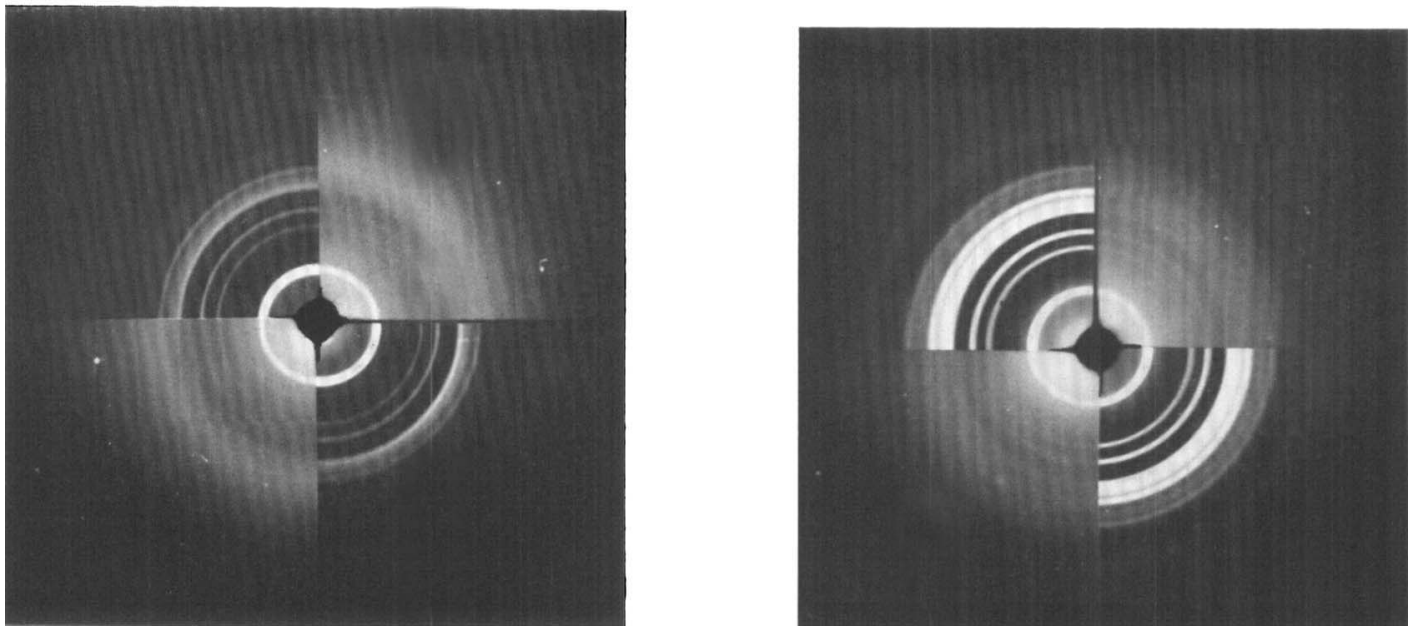

Fig. 4

W. S. BERTAUD AND OTHERS

Fig. 5 


\section{EXPLANATION OF PLATES}

\section{Plate 1}

Fig. 1. Replica of a natural spore of Pithomyces chartarum showing the dense coating of spicules. $(\times 13,000$. $)$

Fig. 2. Profile view of a whole natural spore showing how the spicules project from the surface. $(\times 30,000$.

\section{Plate 2}

Fig. 3. Replica of a spore washed for $1 \mathrm{hr}$. in diethyl ether. Many of the cuticular protuberances have been detached and are embedded in the replica. $(\times 13,000$.

Fig. 4. X-ray diffraction pattern comparing crystalline total sporidesmolide fraction, top left and bottom right, with whole spores.

Fig. 5. X-ray diffraction pattern comparing crystalline total sporidesmolide fraction, top left and bottom right, with a spore replica containing spicular material as described in the text. 